TRADISIONELE LEIERS: ERKENNING EN DIE PAD VORENTOE

ISSN 1727-3781

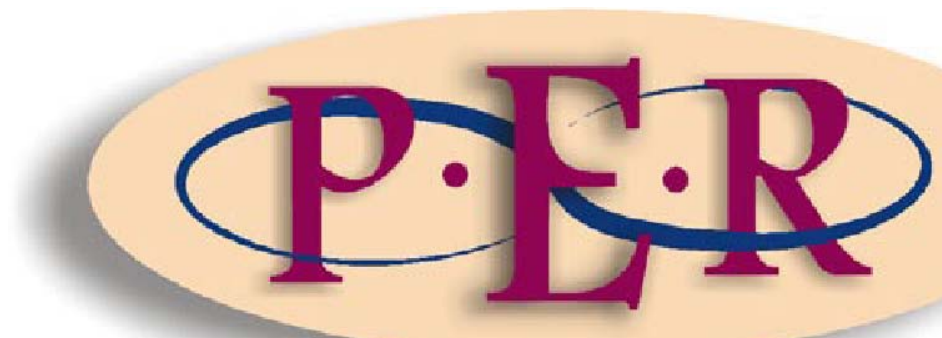

1998 VOLUME 1 No 1 


\section{TRADISIONELE LEIERS: ERKENNING EN DIE PAD VORENTOE}

TE Scheepers en W du Plessis ${ }^{*}$

\section{$1 \quad$ Inleiding}

Amptelike grondwetlike erkenning is vir die eerste keer in die Grondwet van die Republiek van Suid-Afrika 200 van $1993^{1}$ aan tradisionele leiers verleen. Voorheen was die erkenning van tradisionele leiers deur die Swart Administrasie Wet 38 van 1927 en die verskeie Grondwette van die TBVC-state ${ }^{2}$ gereël.

Die instelling van tradisionele leiers is kontroversieel. Moderniste is van mening dat die instelling van tradisionele leiers uitgedien is terwyl dit steeds erken en gerespekteer word deur die verskillende gemeenskappe in Suid-Afrika. Hierdie tweespraak het geblyk uit 'n ondersoek van die Traditional Authorities Research Group in die Noordelike Provinsie, Provinsie van die Noordwes en KwaZulu-Natal. 'n Tradisionele leier word gesien as kgosi ke kgosi ka batho ('"n leier is 'n leier deur sy mense"), die vader van sy mense en 'n samebindende faktor wat as simbool van die eenheid van die groep dien.

* Fakulteit Regte, PU vir CHO.

1 A 181.

2 Transkei, Venda, Ciskei en Bophuthatswana

3 Die lede van die ondersoekspan was D Balatseng (Universiteit van die Noordweste); J Chiumya (Universiteit van die Noorde); W Du Plessis (PU CHO); B De Wet (Universiteit van die Noorde); G Ferreira (PU CHO); L Jansen van Rensburg (PU CHO); S Luthuli (Universiteit van Zululand); M Mabiletsa (Universiteit van die Noorde); K Mojela (Universiteit van die Noorde); P Mtsaulana (Universiteit van die Noorde); R Ndou (Universiteit van die Noorde); S Nzimande (Universiteit van Zululand); N Olivier (Universiteit van Natal - Pietermaritzburg); B Oomen (Van Vollenhoven Instituut voor Recht in Niet-Westerse Landen -Universiteit van Leiden, Nederland); J M Otto (Van Vollenhoven Instituut voor Recht in Niet-Westerse Landen, Universiteit van Leiden, Nederland); C Rautenbach (PU CHO); D Selala (Universitiet van die Noordweste); TE Scheepers (PU CHO); J van den Heever (Universiteit van die Noorde); A van der Walt (PU CHO); J Williams (Universiteit van Natal - Pietermaritzburg). Die verslag bestaan uit 14 volumes en staan bekend as die Traditional Authorities Research Group The administrative and legal position of Traditional Authorities in South Africa and their contribution to the implementation of the Reconstruction and Development Programme (1996). Die stellings wat in hierdie aantekening gemaak word, is hoofsaaklik gebaseer op die empiriese navorsing en literatuurstudies wat gedoen is. 
Tradisionele leiers vervul ' $n$ verskeidenheid van funksies in stamme, samelewings en gemeenskappe. Die vernaamste van hierdie funksies het te make met hulle rol as regsprekende amptenare in tradisionele howe, beslegters van geskille buite die hof, religieuse leiers van die gemeenskap, politieke leiers van die lede van die stam, draers van die hoogste gesag oor die toekenning en gebruik van grond onder sy (of haar ) jurisdiksie, en as daardie persoon wat in die laaste instansie verantwoordelik is vir die welsyn en ontwikkeling van alle lede van die stam. Die wetlike bepalings wat erkenning aan tradisionele owerhede verleen, verander nie aan hierdie posisie van tradisionele leiers nie, behalwe om deur die erkenning van tradisionele leiers en Afrika gewoontereg die posisie van tradisionele leiers, as deel van die Suid-Afrikaanse samelewing te bevestig.

Dit blyk uit navorsing wat in verskeie ander jurisdiksies (Afrika, Asië en Suid-Amerika) gedoen is, dat waar regerings gepoog het om die stelsel van tradisionele leierskap uit te wis of om hulle jurisdiksie te ontneem dit nie die gewenste uitwerking gehad het nie. Telkens het die instelling weer na vore gekom.

Ontwikkeling van die landelike gemeenskappe is een van die prioriteite van die regering. Hierdie ontwikkeling kan slegs slaag indien die gemeenskappe self 'n rol daarin kan speel. Die tradisionele leier het ' $n$ belangrike rol hierin te speel.

In hierdie artikel word daar 'n kort oorsig oor die Swart Administrasie Wet 38 van 1927 en die grondwetlike posisie van 1993 en 1996 gegee en daarna word die rol wat die tradisionele leier na aanleiding van die Grondwet in ontwikkeling kan speel, bespreek.

\section{Erkenning van tradisionele leiers}

\subsection{Swart Administrasie Wet 38 van 1927}

4 In KwaZulu-Natal is daar volgens mededeling deur Nkosi Ngubane tydens vraetyd by die internasionale konferensie oor tradisionele leierskap in Suider-Afrika 16 - 18 April te Umtata, tans ses vroulike tradisionele leiers net in daardie provinsie alleen. Alle verwysings na hy/hom sluit ook sy/haar in.

5 Vgl ook Vorster 1996 SA Tydskrif vir Etnologie 76. 
Die eerste amptelike erkenning van tradisionele leiers is in artikel 2(7) van die Swart Administrasie Wet 38 van 1927 verleen. Die President word gemagtig om tradisionele leiers vir stamme of gemeenskappe aan te wys en kan ook die pligte, bevoegdhede en voorregte uiteensit en voorwaardes vir die uitoefening van die amp daarstel. In die meeste gevalle het die vorige staatspresidente uitvoering gegee aan die besluit van die stam. Die artikel is egter van tyd tot tyd gedurende die "apartheidsjare" deur beide die SuidAfrikaanse regering en die sogenaamde "onafhanklike" state misbruik om van teenstanders ontslae te raak.

Die tradisionele leiers en die stamrade, streeks- en gebiedsowerhede ${ }^{7}$ het heelwat bevoegdhede verkry. Alhoewel die bevoegdhede sekere ontwikkelings- en plaaslike owerheid funksies ingesluit het, was die stamme as gevolg van 'n gebrek aan finansies en opleiding nie altyd in staat om daarvan gebruik te maak nie. Die Swart Administrasie Wet het verder aan die tradisionele leier strafregtelike en siviele bevoegdhede verleen. ${ }^{8}$

Tradisionele owerhede is deur die staat betaal - dit was 'n ander wyse waarop beheer oor tradisionele owerhede vanaf sentrale regeringskant uitgeoefen kon word.

\subsection{Grondwet van die Republiek van Suid-Afrika 200 van 1993}

Artikel 181 van die 1993 Grondwet het erkenning verleen aan tradisionele owerhede wat volgens die inheemse reg geleef het en aan wie voor die inwerkingtreding van die 1993 Grondwet reeds erkenning verleen is. Die erkenning was onderhewig gestel aan die moontlikheid van hersiening, herroeping of wysiging. Artikel 181(2) het bepaal dat inheemse reg onderhewig is aan regulering deur die reg.

$6 \quad$ Vgl bv Chief Pilane $v$ Chief Linchwe and Another 19954 SA 686 (B); en daaroor Balatseng en Du Plessis 1996 THRHR 349-355; Vorster 1996 SA Tydskrif vir Etnologie 78.

7 Ingestel kragtens a 2 van die Wet op Swart Owerhede 68 van 1951.

8 A 20. 
Die 1993 Grondwet het voorsiening gemaak vir die erkenning van tradisionele owerhede op nasionale, provinsiale en plaaslike vlak. Voorsiening word gemaak vir die ex officio verteenwoordiging van sekere tradisionele leiers op plaaslike owerhede, ${ }^{9}$ die instelling van 'n Nasionale Raad van Tradisionele Leiers ${ }^{10}$ asook vir Provinsiale Huise van Tradisionele Leiers. $^{11} \quad$ Die Nasionale Raad van Tradisionele Leiers is in April 1997 aangewys. Die vertraging in die samestelling van die raad was te wyte daaraan dat sekere provinsies gesloer het om provinsiale Huise van Tradisionele Leiers aan te wys (bv die Noordelike Provinsie en die Oos-Kaap).

Die Wet op die Nasionale Raad van Tradisionele Leiers 31 van 1994 maak voorsiening vir 'n raad wat uit 19 lede en 'n verkose voorsitter bestaan. Die funksies van die raad is die soos omskryf in artikel 184 van 1993 Grondwet naamlik om die nasionale regering oor enige aangeleentheid wat tradisionele leiers raak of die tradisies en gebruike van tradisionele gemeenskappe te enige plek in die Republiek te adviseer. Hulle moet op versoek van die President advies gee oor enige aangeleentheid van nasionale belang. Die President mag reëls uitvaardig rakende die samestelling van die kieskollege en die stemprosedure. Die raad word al om die vyf jaar saamgestel. In 1997 is 'n nuwe Wet op die Raad van Tradisionele leiers 10 van 1997 gepubliseer wat Wet 31 van 1994 herroep het. $^{13}$ Die doel van die nuwe wetgewing is om die probleme wat bestaan het met die samestelling van ' $n$ raad uit die weg te ruim deur voorsiening te maak dat elke provinsiale huis lede op die Nasionale Raad benoem.

Die provinsiale huise moes telkens geraadpleeg word oor wetgewing in die provinsie wat hulle raak. $^{15}$ Indien daar besware is teen sodanige wetgewing moet die besware binne 30 dae ingedien word. Die wetsontwerp kan dan nie binne 'n verdere 30 dae aanvaar word nie. Dit is nie duidelik wat met die besware van die huise moet gebeur nie en wat sou gebeur indien die besware nie binne 30 dae bygelê kan word nie. Die

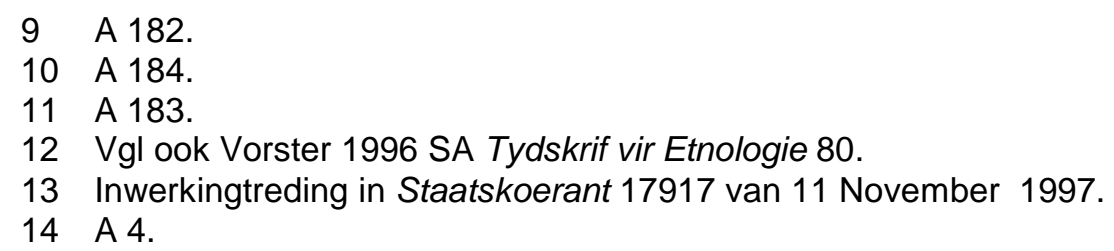


artikel het dus in effek geen "tande" nie. Die huis kan verder die provinsiale regering adviseer oor aangeleenthede wat die tradisionele gemeenskappe, inheemse reg of die tradisies van die gemeenskappe in die provinsie raak. Dit wil voorkom asof beide die nasionale en provinsiale wetgewers hierdie bepaling geïgnoreer het en dat geen wetgewing wat tradisionele gemeenskappe raak aan hulle voorgelê word nie.

'n Provinsiale regering het kragtens die 1993 Grondwet die wetgewende bevoegdheid gehad om wetgewing oor inheemse reg en tradisionele leiers te maak. ${ }^{16}$ Artikel 160(3)(b) bepaal dat 'n provinsiale Grondwet voorsiening kan maak vir die instelling, rol, bevoegdhede en status van 'n tradisionele monarg en dat in die geval van KwaZulu-Natal sodanige erkenning van die Zulu monarg vervat moet wees.

In 1995 is die Nasionale Wet op die Betaling van Tradisionele Leiers 29 of 1995 uitgevaardig. ${ }^{17}$ Die voorwoord van die wet lui soos volg:

WHEREAS the importance for the well-being and equity of the South African Nation of the role of traditional leaders in the governance, guidance and representation of those wishing to maintain their bonds with their traditional land and communities and to subject themselves to the authority of traditional hierarchies is acknowledged;

AND WHEREAS the subjects and followers of particular tribal authorities do not necessarily all reside in a single province and the constituencies of traditional hierarchies transcend provincial boundaries;

AND WHEREAS the need for members of traditional hierarchies to be supported, maintained and remunerated in respect of their tribal roles from national governmental level and from national funds as opposed to the provincially administered statutory functions they may fulfil and in respect

15 A 183.

16 A 126 gelees met bylae 6 .

17 Inwerkingtreding 28 Desember 1995. 
of which they may be remunerated by provincial or local governments is recognised.

'n Tradisionele leier is gedefinieer as "any person who in terms of indigenous law or any other law holds a position in a traditional ruling hierarchy". ${ }^{18}$ Die wet maak voorsiening dat die President die betaling en toelae van tradisionele leiers in samespraak met die Raad van Tradisionele Leiers en die Vergoedingskommissie ${ }^{19}$ moes goedkeur. Die betaling geskied uit die Nasionale Reserwe Fonds. ${ }^{20}$ Die President kan 'n onderskeid tref tussen die verskillende kategorieë tradisionele leiers op grond van hulle status en bevoegdhede.

KwaZulu-Natal het eie wetgewing aanvaar waarin daar voorsiening gemaak is vir die betaling van tradisionele leiers deur die betrokke provinsie. ${ }^{22}$ Daar is ook spesifiek melding gemaak dat die tradisionele leiers nie geregtig sou wees om enige fondse buite dié provinsie te ontvang nie. Die aangeleentheid het in die Konstitusionele Hof gedraai. In Ex Parte Speaker of the KwaZulu-Natal Provincial Legislature: In re KwaZulu-Natal Amakhosi and Iziphakanyiswa Amendment Bill of 1995; Ex Parte Speaker of the KwaZulu-Natal Provincial Legislature: In re Payment of Salaries, Allowances and other Privileges to the Ingonyama Bill of $1995^{23}$ het die Konstitusionele Hof bevind dat die provinsie kragtens artikel 126 gelees met bylae 6 wel geregtig is om wetgewing oor tradisionele leiers te maak en dat die provinsiale wetgewing in hierdie geval voorrang geniet het.

\subsection{Grondwet van die Republiek van Suid-Afrika 108 van $1996^{24}$ ()}

18 A 1.

19 A 2071993 Grondwet.

20 A 2(1).

21 A 2(2)(a)-(b). Op 1997-07-11 is 'n kennisgewing deur die Vergoedingskommissie uitgereik waarin aanbeveel word dat 'n span aangestel word om die struktuur, rol, bevoegdhede en pligte van tradisionele leiers in Suid-Afrika te ondersoek. Daar word tot tyd en wyl die verslag ontvang word 'n betalingstruktuur voorgestel waarvolgens bv die KwaZulu-Natal monarg R300 000 per jaar ontvang en ander stamhoofde R144 000 per jaar. Grade vir betaling van 'n stamkaptein "chief" en hoofman word ook aangedui. Indien 'n stamhoof se betaling tans (wettig) op 'n groter bedrag vasgestel is, word die nuwe betaling tav die persoon se opvolger geïmplementeer.

22 KwaZulu-Natal Amakhosi and Iziphakanyiswa Amendment Bill of 1995 en die Payment of Salaries, Allowances and other Privileges to the Ingonyama Bill of 1995.

2319964 SA $653(\mathrm{KH})$.

24 Hierna 1996 Grondwet. 
Die bepalings van die 1996 Grondwet verskil substansieel van die in die 1993 Grondwet. 'n Minimalistiese benadering is gevolg. Die instelling, status en rol van tradisionele leierskap volgens die inheemse reg word erken onderhewig aan die bepalings van die 1996 Grondwet. $^{25}$ 'n Tradisionele owerheid wat 'n stelsel van inheemse reg navolg, mag funksioneer onderhewig aan enige toepaslike wetgewing en gebruike, asook wysigings en herroepings in wetgewing. ${ }^{26}$ Nasionale wetgewing kan voorsiening maak vir die rol van tradisionele leierskap as ' $n$ instelling op plaaslike vlak waar plaaslike gemeenskappe geraak word. ${ }^{27}$ Nasionale of provinsiale wetgewing kan huise van tradisionele leiers instel en nasionale wetgewing kan voorsiening maak vir die daarstelling van 'n raad van tradisionele leiers om sake te hanteer rakende leierskap, die rol van tradisionele leiers, inheemse reg en die gebruike van gemeenskappe wat 'n stelsel van inheemse reg navolg.

Die 1996 Grondwet spel nie duidelik uit wat die bevoegdhede en die rol van tradisionele leiers is nie. Veral op plaaslike vlak bestaan daar probleme omdat die skeidslyn tussen die funksies van plaaslike owerhede en tradisionele leiers glad nie afgebaken is nie.

Daar is geen verpligting op die provinsies om wel huise van tradisionele leiers op te rig nie. Veral in die provinsies waar daar die moderniste ' $n$ meerderheid het, is die oprigting van sodanige huise hewig teengestaan.

Tradisionele leierskap word onderhewig gestel aan die 1996 Grondwet, dus ook aan fundamentele regte en demokratiese beginsels. Tradisionele leiers se posisie word erfregtelik bepaal ${ }^{31}$ en dit wil voorkom asof daar dus 'n konflik in artikel 211 bestaan. Vorster $^{32}$ en Bennett ${ }^{33}$ is van mening dat die grondwetskrywers tradisionele leierskap

25 A 211(1).

A 211(3).

A 212(2).

A 212(2)(a)-(b).

29 Vgl ook Mtimkulu 1996 Politeia 89-93; Vorster 1996 SA Tydskrif vir Etnologie 79.

30 Vgl ook Mtimkulu 1996 Politeia 90.

31 Die oudste seun in die manlike linie erf volgens die beginsel van eersgeboortereg.

321995 SA Tydskrif vir Etnologie 79. 
as 'n uitsondering op die beginsel van vrye en demokratiese verkiesings beskou. Indien 'n blote interpretasie van die artikel hierdie aanname gevolg word, sal demokratiese beginsels voorrang moet geniet. Daar sou 'n beroep op artikels 30 en 31 (reg op kultuur) gemaak kan word, maar hierdie artikels word onderhewig aan fundamentele regte (dus ook reg op gelykheid) gestel.

Daar word in die 1996 Grondwet voorsiening gemaak vir konkurrente ${ }^{34}$ en uitsluitlike wetgewende funksionele gebiede ${ }^{35}$ waaroor slegs die provinsies wetgewing kan uitvaardig. ${ }^{36}$ Inheemse reg, gewoontereg en tradisionele leierskap onderhewig aan artikel 12 van die Grondwet is almal bylae 4 funksionele gebiede. Die provinsies kan dus wetgewing maak waarin ontwikkelingsbevoegdhede aan tradisionele leiers verleen word.

Artikels 146 tot 150 hanteer die interpretasie van die konflik tussen nasionale en provinsiale wetgewing en kan moontlik die probleme oplos wat deur die KwaZulu-Natal saak navore gebring is.

\section{Rol van tradisionele leiers in ontwikkeling}

Die gemeenskappe waarmee onderhoude gevoer is, het duidelik laat blyk dat hulle regeringsinmenging (veral deur persone wat geen benul het van die tradisionele samelewing en hulle waardes) verwerp. Die beginsel van deelname en konsultasie voordat wetgewing en beleid opgestel en deurgevoer word, vorm 'n belangrike deel van die voorstelle.

Die tradisionele leier speel wel 'n rol in die ontwikkeling en ontwikkelingsbeplanning van die tradisionele owerheidsgebied waarvoor hy verantwoordelik is. ${ }^{39}$ Die

33 Human Rights 71-72.

34 Bylae 4 waaroor beide die provinsie en die nasionale wetgewer wette kan maak.

35 Bylae 5.

36 A 104(1)(b); vgl ook a 104(4)-(5) en 44(3).

37 Vgl 2.2.

38 Die tradisionele leiers behoort hulle nie met partypolitiek te assosieer nie vanweë hulle rol in die tradisionele gemeenskappe. Daarom behoort hulle neutraal van politiek te staan.

39 Scheepers Traditional Leadership. 
tradisionele leier word deur die lede van sy stam verantwoordelik gehou vir die ontwikkeling van die stamgebied. ${ }^{40}$

Alhoewel daar nie uitdruklik in die wetgewing en die 1996-Grondwet riglyne gegee word oor die onderskeid tussen funksies van tradisionele en ander politieke leiers nie, vind sodanige verdeling wel in die praktyk by die implementering van nuwe wetgewing plaas, soos in die geval van die Wet op Ontwikkelingsfasilitering 67 van $1995^{41}$ en die Oorgangswet op Plaaslike Regering 209 van 1993 . $^{42}$ Al hoe meer praktiese reëlings word getref om hierdie wetgewing tot uitvoer te bring in samewerking met die tradisionele leiers van die betrokke gebied. ${ }^{43}$ 'n Distriksraad wat se gebied landelike tradisionele owerheidsgebiede insluit, moet grondgebruiksdoelwitte ingevolge artikel 28 van die Wet op Ontwikkelingsfasilitering formuleer. ${ }^{44}$ Die formulering van hierdie doelwitte geskied volgens die ontwikkelingsbeginsels vervat in artikel 3 van die Ontwikkelingsfasiliteringswet. Volgens hierdie beginsels moet alle gemeenskappe (en derhalwe ook hulle leiers) gekonsulteer word en moet die gemeenskap se belange, behoeftes en prioriteite in die ontwikkeling- en beplanningsproses geakkommodeer word. Ten einde te verseker dat ontwikkelingsprojekte werklik gemeenskapsgebaseer is en deur die mense wat daarby betrokke is gedryf sal word, ${ }^{45}$ kan 'n distriksraad nie anders as om tradisionele leiers by die beplanningsproses te betrek nie. Ook wanneer geïntegreerde ontwikkelingsplanne ${ }^{46}$ opgestel word vir 'n gebied sal die onderskeie substreke van 'n distriksraadgebied nie geraadpleeg en betrokke kan wees as die tradisionele leiers (as verteenwoordigers van die inwoners van daardie gebiede) nie by die formuleringsproses betrek word nie. Die noodsaaklikheid van gemeenskapsbetrokkenheid by die beplanning van ontwikkeling op plaaslike vlak hou ten nouste verband met die funksie-omskrywing van die rol van plaaslike owerhede

40 Traditional Authorities Research Group Administrative and legal position vol VIII 86 -87.

41 Het in werking getree op 22 Desember 1995 - Prokl R 111 van 22 Desember 1995.

42209 van 1993; het in werking getree 2 Februarie 1994 - Prokl 174 van 30 November 1994.

43 Een so voorbeeld is die proses wat tans onder leiding van die Rustenburg Distriksraad plaasvind as deel van die beplanning van en strategiese ontwerp vir die landelike gebiede binne die jurisdiksiegebied van daardie raad.

4467 van 1995 Hfst 4 - a 28 gelees met a 3.

45 Sien oor gemeenskapsgebaseerde ontwikkelingsproses die Mandela Village gevallestudie soos beskryf deur Hogg Focus Forum RGN 4(1):9-12. 
soos omskryf in die 1996 Grondwet $^{47}$ as onder andere "to promote social and economic development" en "to encourage the involvement of communities and community organizations in the matters of local government".

Die 1996-Grondwet erken tradisionele owerhede en die rol wat hulle binne hulle tradisionele gemeenskappe speel. Beide die formele en informele erkenning wat verleen word, bring mee dat hulle nie in ontwikkeling geïgnoreer kan word nie.

Tradisionele leiers kan 'n definitiewe rol te speel op die nasionale, provinsiale en plaaslike vlakke van die regering. Op nasionale en provinsiale vlak kan hulle meer betrek te word in die formulering en besluitnemingsprosesse rakende aangeleenthede wat hulle raak. Op plaaslike vlak kan hulle toe te sien dat die beleid behoorlik geïmplementeer word veral waar dit die ontwikkeling van hulle gebiede raak. Die beginsel dat die regering nader aan die mense op voetsoolvlak gebring word, is veral belangrik waar die tradisionele gemeenskappe ter sprake is.

\section{Gevolgtrekking}

Die mate waartoe tradisionele leiers meer moderne leierskapstake suksesvol uitvoer, hang nou saam met vorige ondervinding in en blootstelling aan, asook bemagtigingsgeleenthede wat vir so 'n leier in die ontwikkelingswêreld gebied word. Die ontwikkeling van vaardighede om suksesvol aan die ontwikkelingsbeplanningsproses te kan deelneem, vind nie net by wyse van formele opleidingsgeleenthede plaas nie maar kan heel dikwels as deel van beplanningsessies (of gelyktydig daarmee saam) plaasvind.

Die rol van die tradisionele leiers in Suid Afrika as gemeenskapsleiers het wel 'n politieke sowel as 'n sosiaal-religieuse aspek. Alhoewel die mening soms gehuldig word dat tradisionele leiers nie direk in partypolitiek betrokke behoort te wees nie,

46 A 10B van die Tweede Wysigingswet van die Oorgangswet op Plaaslike Owerhede 97 van 1969 -Prokl 1896 van 22 November 1996.

$47 \quad$ A 152(1) (c) en (e).

48 Soos hierbo vermeld as een van die standpunte wat na vore gekom het tydens die TARG ondersoek - vgl 2.1. 
is dit in die praktyk, veral nou dat partypolitiek op plaaslike owerheidsvlak 'n relatief oorheersende rol speel, nie moontlik om die rol van die tradisionele leier as plaaslike leier totaal uit die politieke arena te hou nie. Die rede hiervoor is enersyds omdat sosiale, ekonomiese, religieuse, politieke, kulturele en gewoontereg kwessies nie duidelik in Afrosentriese denke onderskei word nie en gewoonlik as geïntegreerde geheel na vore kom. Andersyds is dit nie moontlik om die leierskapsrol van tradisionele leiers van politiek te skei nie, omdat kultuur en waardes van gemeenskappe bepalende faktore is wat sal bepaal of wetgewing, beleid, ontwikkelingsplanne en selfs ontwikkelingsprojekte vir ' $n$ gemeenskap aanvaarbaar is en of die betrokke gemeenskap wel eienaarskap daarvoor sal aanvaar al dan nie.

Al die provinsies van Suid-Afrika waar tradisionele owerheidsgebiede deel van hulle grondgebied uitmaak, het wetgewing aanvaar na aanleiding waarvan Provinsiale Huise van tradisionele leiers gestig is. Hierdie huise is almal verteenwoordig in die Nasionale Raad van Tradisionele Leiers. ${ }^{50}$ Dit is weliswaar so dat die magte wat volgens wet aan tradisionele leiers op nasionale vlak deur die nasionale regering toegewys word, hoogstens adviserend is en weinig werklike besluitneming en uitvoerende magte bevat Dit word egter in oorweging gegee dat hierdie stap ' $n$ duidelike beginpunt is wat ruimte laat vir 'n groter rol vir tradisionele leiers op nasionale en provinsiale vlak na mate meer vertroue, respek en 'n waardering vir die amp en posisie van tradisionele leiers ontstaan, en bewerkstellig word.

Net soos wat tradisionele leiers trustees is van die gewoontereg en waardes wat die gemeenskap oor jare heen aan hulle toevertrou het, is hulle in landelike tradisionele owerheidsgebiede ook die bewakers van die waardes onderliggend aan die Grondwet en veral die handves van menseregte soos vervat in hoofstuk 2 van die 1996 Grondwet. Die tradisionele Afrika-waardesisteem het 'n hele aantal raakpunte met

49 Vgl Pityana Many Cultures, One Nation 167 wat daarna verwys dat ontwikkelings en ontwikkelingswaardes wêreldwyd ' $n$ taak is waarmee regerings op plaaslike vlak hulle moet besig hou.

50 Wet op die Nasionale Raad van Tradisionele Leiers 10 van 1997.

51 Grondwet van die Republiek van Suid Afrika 108 van 1996 7-39, asook waarskynlik die beginsels onderliggend aan die Grondwet; dit kan 'n belangrike rol speel in die skep van die regte gesindheid en bewustheid wat nodig is om die grondwetlike beginsels en bepalings op voetsoolvlak tot uitvoer te bring. 
die waardes soos vervat in die handves en 1996 Grondwet; $^{52}$ veral die onderliggende redes vir sekere inheemse gebruike kan in meeste gevalle gebruik word om 'n brug te slaan tussen tradisionele en moderne menseregtekonsepte sonder dat daar gewag word vir die normale evolusionêre proses van regsontwikkeling op die gebied van Afrika gewoontereg of bepalings van die inheemse Afrikareg. 'n Vergelyking van inheemse gewoontereg met beginsels soos vervat in die handves van fundamentele regte en ' $n$ soms oorhaastige verdoeming van gebruike onder nie-westerse gemeenskappe, moet liefs plaasvind met inagneming van die gelykstelling in die Grondwet van die inheemse reg en (ander) geloofsgebaseerde regsinstellings aan die gemenereg van Suid-Afrika.

Dit is in die lig van hierdie benadering wat die dilemma van tradisionele leiers verstaan moet word wanneer hulle nieteenstaande hulle plig om 'n kultuur van fundamentele regte te help skep, nie summier kulturele en gemeenskapswaardes oorboord kan gooi nie. Regsverandering is immers nie die funksie of taak van die tradisionele leier nie; die skep en verandering van regsreëls moet vanuit die gemeenskap kom en moet die sanksie van die hele volk (stam) geniet voordat die tradisionele leier sy of haar stempel daarop kan plaas.

Op die gebied van ontwikkeling van mense, gebiede, fasiliteite en infrastruktuur op plaaslike en provinsiale vlak is daar, nieteenstaande die gebrek aan duidelike riglyne in tersaaklike wetgewing, min twyfel dat daar vir tradisionele leiers sowel as vir demokraties verkose leiers 'n ewe belangrike rol is om te vervul teenoor die gemeenskappe wat deur hulle bedien en gedien word. Albei hierdie groeperings van die leierskorps op plaaslike vlak, is immers verantwoordelik aan dieselfde gemeenskap terwyl hulle posisie as leier, gekose of vererf, sy ontstaan het binne daardie selfde gemeenskappe. Alhoewel daar soms oorvleueling van verantwoordelikhede en sommige take op samelewingsvlak mag wees, kan die tradisionele leier nie die statutêr omskrewe rol van die demokraties verkose leier speel nie, en vice versa.

52 Dlamini Human Rights 22, 23. 
Die rol van tradisionele leiers as instelling in Suid-Afrika mag dalk nie duidelik in beleidsdokumente en wetgewing omskryf word nie, maar sal in die toekoms al hoe duideliker uitkristalliseer namate daar op die erkenning wat in die 1996 Grondwet aan tradisionele leiers (en inheemse reg) verleen word en die vindingrykheid van plaaslike owerheidsbeplanners in landelike gebiede (wanneer gemeenskappe by die ontwikkelingsproses betrek moet word) voortgebou word. Die mate waartoe tradisionele leiers pro-aktief by die ontwikkelingsproses betrokke raak en hulself bewys as gewillige en diensvaardige ontwikkelingsagente, sal ook stukrag verleen aan die oproep van landelike mense om toegelaat te word om verantwoordelikheid en eienaarskap te aanvaar vir die ontwikkeling van landelike tradisionele owerheidsgebiede en die inwoners van daardie gebiede. Die realiteite van die behoeftes en waardes van plaaslike gemeenskappe sal weldra deur die wetgewer in toepaslike wetgewing vervat moet word sodat regsmaatreëls en meganismes op sigbare en effektiewe wyse grondwetlike beginsels waar kan maak, ook in gebiede onder die jurisdiksie van tradisionele leiers. 


\section{BIBLIOGRAFIE}

Balatseng en Du Plessis 1996 THRHR 349-355 Balatseng D en Du Plessis W Succession of chieftaincy: hereditary, appointment or by common consent? -Chief Pilane $v$ Chief Linchwe and Another 19954 SA 686 (B) 1996 THRHR 349-355

Bennett Human Rights Bennett TW Human Rights and African Customary Law (Juta Kaapstad 1995)

Dlamini CRM Human Rights Dlamini CRM Human Rights in Africa (Butterworths Durban 1995)

Hogg Focus Forum RGN

Hogg G "Real People Driven Development is Possible" in Focus Forum RGN 4(1):912

Mtimkulu 1996 Politeia 89-93 Mtimkulu P "Traditional leaders and the Constitution" 1996 Politeia 89-93

Pityana Many Cultures, One Nation Pityana NB "Minorities in Global Societies" in VillaVicencio C en Niehaus C (reds) Many Cultures, One Nation (Human \& Rousseau Kaapstad 1995) 167

Scheepers Traditional Leadership Scheepers TE "Traditional Leadership and the Development Process in South Africa" Ongepubliseerde referaat gelewer by die internasionale konferensie oor tradisionele leierskap in Suider-Afrika 16-18 April 1996 Umtata

Scheepers 1996 SA Publiekreg 490-511 Scheepers TE "Die rol van die reg in die ontwikkeling van landelike tradisionele owerheidsgebiede" 1996 SA Publiekreg 490511 
Traditional Authorities Research Group Administrative and legal position

Traditional Authorities Research Group The administrative and legal position of Traditional Authorities in South Africa and their contribution to the implementation of the Reconstruction and Development Programme

(Potchefstroom 1996)

Vorster 1996 SA Tydskrif vir Etnologie 76 Vorster LP "Tradisionele leierskap in SuidAfrika" 1996 SA Tydskrif vir Etnologie 76

Whitfield South African Native Law Whitfield GMB South African Native Law (Juta Kaapstad 1929) 2

\section{Hofsake}

Chief Pilane v Chief Linchwe and Another 19954 SA 686 (B) 19964 SA 653 (KH) Ex Parte Speaker of the KwaZulu-Natal Provincial Legislature: In re KwaZulu-Natal Amakhosi and Iziphakanyiswa Amendment Bill of 1995; Ex Parte Speaker of the KwaZulu-Natal Provincial Legislature: In re Payment of Salaries, Allowances and other Privileges to the Ingonyama Bill of 199519964 SA $653(\mathrm{KH})$

\section{Wette}

Grondwet van die Republiek van Suid-Afrika 200 van 1993

Grondwet van die Republiek van Suid-Afrika 108 van 1996

KwaZulu-Natal Amakhosi and Iziphakanyiswa Amendment Bill of 1995

Oorgangswet op Plaaslike Regering 209 van 1993

Payment of Salaries, Allowances and other Privileges to the Ingonyama Bill of 1995

Swart Administrasie Wet 38 van 1927

Wet op die Raad van Tradisionele Leiers 10 van 1997

Wet op Nasionale Raad van Tradisionele leiers 31 van 1994

Wet op Ontwikkelingsfasilitering 67 van 1995

Wet op Swart Owerhede 68 van 1951 


\section{Proklamasies}

Prokl 174 Staatskoerant 16093 van 30 November 1994 Prokl R111 Staatskoerant 16880 van 22 Desember 1995 Prokl 1896 Staatskoerant 17607 van 22 November 1996

p:lartikellgwtl971.doc 